\title{
TRANSFUSIONAL HAEMOSIDEROSIS SIMULATING HAEMOCHROMATOSIS
}

\author{
BY \\ J. TREVOR HUGHES AND LESLIE H. TRUELOVE \\ From the Departments of Morbid Anatomy and Medicine, Stoke Mandeville Hospital, Aylesbury, Bucks
}

(RECEIVED FOR PUBLICATION JUNE 24, 1957)

Haemochromatosis is a disease occurring predominantly in men, and characterized by excessive deposition of iron in the tissues, coexisting with skin pigmentation and hepatic, pancreatic, and testicular fibrosis. The condition is described by Sheldon (1935) in whose monograph 311 cases are reviewed.

Parenteral iron given in excess of requirements will be deposited in the tissues, since, with the exception of menstruation in women, the body has no normal mechanism for the elimination of significant amounts of iron. Except in haemorrhagic states, similar iron deposition will follow multiple blood transfusions. The distribution of this iron and its effect on the tissues is a study of considerable theoretical interest and of some practical importance. On the existence of a type of haemochromatosis known as acquired, secondary, exogenous, or transfusional, opinion is divided. Schwartz and Blumenthal (1948), Aufderheide, Horns, and Goldish (1953), Goldish and Aufderheide (1953), Morningstar (1955), and Pengelly and Jones (1956) have reported cases described as haemochromatosis caused by multiple blood transfusions. That multiple blood transfusions alone can cause haemochromatosis is denied by Wyatt, Mighton, and Moragues (1950), Cottier (1952), Kleckner, Baggenstoss, and Weir (1954), Kleckner, Kark, Baker, Chapman, Kaplan, and Moore (1955), and by Dubin (1955).

The following case is reported of a woman who, having received 150 "pints" of blood for an aplastic anaemia, developed haemosiderosis seen as pigmentation of the skin and detectable in the sternal marrow and mucosal glands of the stomach. Post-mortem examination showed an extensive haemosiderosis with hepatic and pancreatic fibrosis.

\section{Case Report}

A woman of 67 presented with a two years' history of increasing lassitude and pallor. This proved on investigation to be due to an aplastic anaemia. No toxic cause was discovered and the previous medica $\vec{r}$ and family history was not relevant. On examina? tion she was markedly pale. The spleen and live $\vec{N}$ were just palpable on inspiration. A diffuse systolie murmur was audible throughout the precordium. The haemoglobin on admission was $31 \%$, estimated by the oxyhaemoglobin method $(100 \%=14.8 \mathrm{~g} . / 100 \mathrm{ml}$.$) , and$ the white cell count was $2,800 / \mathrm{c}$.mm., of which $48 \%$ were neutrophils. The sternal marrow showed aD normal cellularity with relative hypoplasia of the reto cell series. Free iron was present in the marrowe section but not in excess.

Treatment in the first instance was with iron by mouth, folic acid $15 \mathrm{mg}$. t.d.s., vitamin $B_{12} 100 \mu \mathrm{g}$ daily, and tabs. thyroid sicca $\frac{1}{2}$ grain b.d. There was no evidence that any of these agents either singly on in combination had any influence on the bloop picture, and throughout her long illness the only successful treatment was that of transfusion of bloo $\vec{B}$ given as packed cells, the blood group being $O$ rhesus negative. Transfusions were given at approximatele six-weekly intervals and averaged about five bottles of whole blood, given as packed cells each time, for the next three years. (The National Transfusion Service bottle of whole blood contains approximately $540 \mathrm{ml}$. of which $120 \mathrm{ml}$. is anticoagulant.) During this time. the haemoglobin varied from 25 to $30 \%$ before trans? fusion to 75 to $85 \%$ after; the total white cell counB was remarkably constant at $2,000-2,500 / \mathrm{c}$.mm. with about $50 \%$ neutrophils, and its relatively slight varia tions bore no relationship to the variations in haemoglobin. Platelets remained at about 100,000 c.mm., and reticulocytes were consistently absent on less than $1 \%$. Ferrous sulphate was given by moutho for the first two months only and did not exceed of total of $50 \mathrm{~g}$. During the last year of her life the् transfusions were a little larger and more frequent: and the haemoglobin was some 10 to $15 \%$ higher.

During the first 12 months of the illness 36 bottles? of blood were given. At the end of this time the sternal marrow showed the same picture as on the first admission. Three years from the first admission, and after 110 bottles of blood, pigmentation of the skin became definite, generally of a slaty-brown colour; this was accentuated in the flexures and waso particularly marked around the neck. Biopsy con $-\frac{0}{5}$ firmed free iron-containing pigment situated in the 
dermis. At this time the prothrombin efficiency was $40^{\circ}$ of normal, and was the only abnormal finding suggestive of liver involvement; standard liver function tests were normal. Two months later, after 122 bottles, the sternal marrow showed free iron in great excess of normal, and a glucose tolerance test was performed. After $50 \mathrm{~g}$. of glucose by mouth the blood sugar rose from a fasting level of $67 \mathrm{mg}$./ $100 \mathrm{ml}$. to $126 \mathrm{mg}$. at half an hour, $208 \mathrm{mg}$. at one hour, and fell slowly to $150 \mathrm{mg}$. at two hours. To exclude the possibility that this result was due to a low dietary intake of carbohydrate, the patient took a high carbohydrate diet ( $200 \mathrm{~g}$./day) for a month and the test was repeated with almost identical results. There was no glycosuria during either test. At this time gastric biopsy showed a deep brown pigmentation in the gastric glands; this pigment stained heavily for free iron. From this time onwards she was treated with cortisone, $25 \mathrm{mg}$./day by mouth for four weeks, then $75 \mathrm{mg}$. per day. After eight weeks a fall of only $4 \%$ haemoglobin in the succeeding four weeks was found. The haemoglobin dropped $35 \%$ in the following two weeks, and thereafter the rate of fall of haemoglobin was the same as before this temporary remission. Two months later, 46 months from her first admission and after 146 pints of blood, she suddenly deteriorated ; haemoglobin was $90 \%$, but the white cell count rose to $20,000 /$ c.mm. with a polymorphonuclear leucocytosis, and in spite of penicillin therapy she died within three days. The only indication of a source of infection had been a transient urinary infection six months previously. Possibly the cortisone, although in only moderate dosage, had masked the symptoms. The enlargement of liver and spleen found on first admission had not increased. There had at no time been any clinical evidence of chronic heart failure or venous congestion.

\section{Necropsy Findings}

Necropsy (P.M. 166/56) was performed on August 10, 1956, 24 hours after death.

The body was that of an elderly asthenic woman showing widespread brownish pigmentation, particularly in the flexures, and numerous bruises.

Cardiovascular System.-The pericardium was roughened and covered by a thick, shaggy exudate. The heart weighed $398 \mathrm{~g}$. The valves and chambers were normal apart from a patent interauricular septum, the aperture measuring $1 \mathrm{~cm}$. in diameter. The myocardium was brown.

Respiratory System.-The lungs were moderately congested. The right upper lobe contained a subpleural abscess $1 \mathrm{~cm}$. in diameter.

Digestive System.-The stomach contained altered blood. The intestines were normal.

Liver.-The liver weighed $1,930 \mathrm{~g}$. The surface was smooth and dark brown as was the cut surface. No obvious nodularity was present.
There was no evidence of chronic venous congestion. The gall-bladder and bile ducts were normal.

Pancreas.-The pancreas was dark brown but otherwise appeared normal.

Genito-urinary System. - The left kidney weighed 171 g., the right kidney 199 g. Both showed several cortical abscesses, the largest measuring $1 \mathrm{~cm}$. in diameter. The bladder contained pus and a thick exudate was adherent to the mucosa. The uterus, Fallopian tubes, and ovaries were normal.

Spleen.-The spleen weighed $256 \mathrm{~g}$. It was firm in consistency and dark brown. No enlarged lymph nodes were found in the neck, axillae, or mediastinal, inguinal, or abdominal areas.

Endocrine System.-The thyroid, suprarenals, and pituitary glands appeared normal.

Central Nervous System.-The brain showed slight oedema but was otherwise normal.

\section{Histological Examination}

Sections were stained with haematoxylin and eosin and also were treated by Perles' method for the demonstration of iron. Haemosiderin was identified as a brown pigment which gave the free iron reaction. No brown pigment was found that failed to give the free iron reaction and it was deduced that haemofuscin and lipofuscin pigments were absent.

Heart.-The cardiac muscle contained a moderate amount of haemosiderin, mainly within the muscle cells.

Lungs.- The right lung showed an abscess in the upper lobe. The left lung was congested. Traces of haemosiderin were present in the alveolar septa.

Liver.-The liver showed marked fibrosis in the portal tracts, the fibrous septa of adjacent portal tracts sometimes coalescing (Fig. 1). True pseudo lobulation, as found in hepatic cirrhosis, was not seen. A large amount of haemosiderin was present, mainly among the fibrous septa and within Kupffer cells (Fig. 2). Small amounts of haemosiderin were present in the hepatic parenchymal cells.

Pancreas.-The pancreas showed moderate fibrosis (Fig. 3). A large amount of haemosiderin was present in the increased fibrous stroma. Only small amounts of haemosiderin were present in the pancreatic parenchymal cells (Fig. 4). The islets of Langerhans appeared less cellular than normal and scanty haemosiderin was present within the islet cells. 


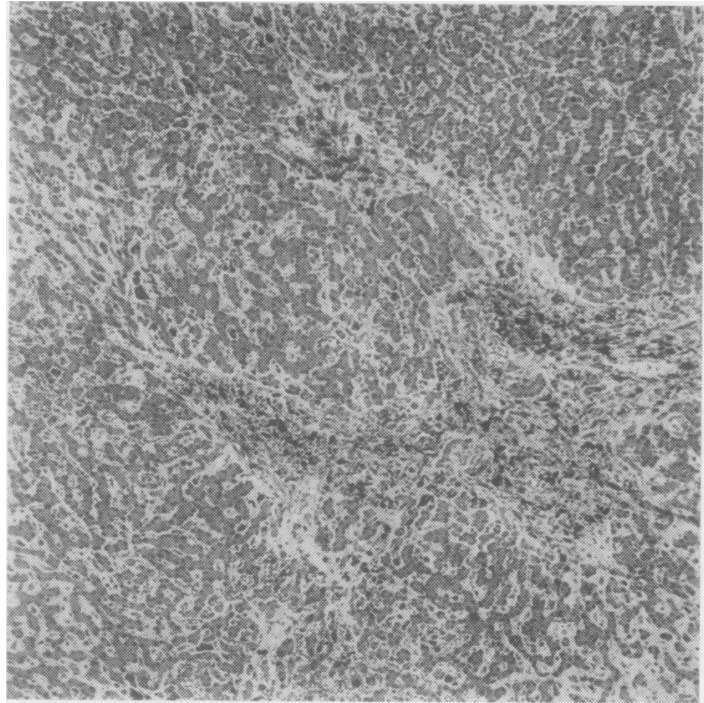

FIG. 1.-Liver stained by haematoxylin and eosin,

50.

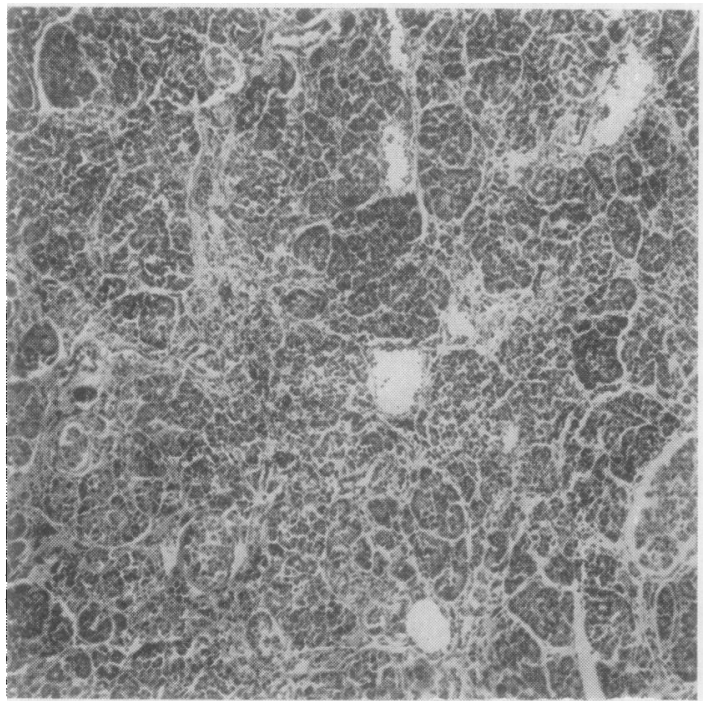

FIG. 3.-Pancreas stained by haematoxylin and eosin, $\times 50$.

Kidneys. - The kidneys showed cortical abscesses. Small amounts of haemosiderin were present in the connective tissue stroma and within the renal tubular epithelium.

Spleen.-The capsule showed moderate thickening, but the fibrous trabeculae were not prominent. The splenic pulp was very congested. A large amount of haemosiderin was present, mainly within phagocytic cells but also lying free in the reticular framework of the spleen.

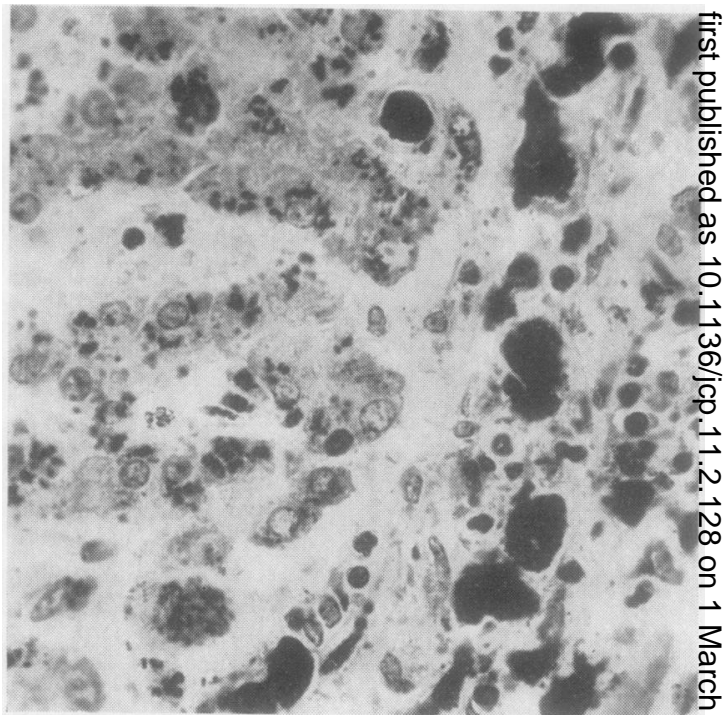

FIG. 2.-Liver stained by Perlss' method, $\times 450$.



FIG. 4.-Pancreas stained by Perles' method, $\because 450$.

Suprarenal Glands. - Moderate amounts of haemosiderin were present, mainly in the parenchymal cells of the adrenal cortex.

Brain.-The brain showed very scanty haemo- $\frac{0}{0}$ siderin pigment.

The examination showed an extensive haemo- $\frac{\stackrel{Q}{\mathbb{D}}}{\sigma}$ siderosis with moderate hepatic and pancreatic $\varrho$ fibrosis. The distribution of iron was widespread, but the greatest amounts were usually in con- 
nective tissues and within phagocytes. No lipofuscin or haemofuscin type pigments were found. The ultimate cause of death was pyaemia.

\section{Iron Analyses}

The iron content of several of the tissues was estimated by the method of Kennedy quoted by Hawk, Oseir, and Summerson (1947). Estimations were performed on random samples of wet tissue and in duplicate except in the cases of the

TABLE I

IRON CONTENT OF TISSUES

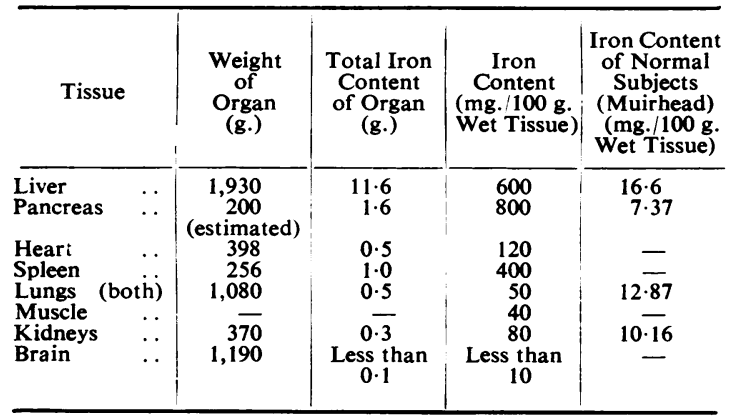

kidney and brain. The results are shown in Table I, in which figures for normal subjects (Muirhead, Crass, Jones, and Hill, 1949) are included.

\section{Conclusions}

The present case shows haemosiderosis with some of the features of haemochromatosis. The latter diagnosis appears unacceptable because of the following features which distinguish this case from haemochromatosis.

Distribution of Haemosiderin.-In this case a large amount of haemosiderin was present in the bone marrow, spleen, and liver, where it was mainly in the portal tracts among fibrous tissue and within Kupffer cells. In haemochromatosis, haemosiderin is not prominent in the bone marrow or spleen and in the liver appears mainly in parenchymal cells. Similarly iron deposition in the pancreas in this case was mainly within phagocytes and free in connective tissue septa.

Mild Degree of Hepatic and Pancreatic Fibrosis.-In haemochromatosis severe portal cirrhosis and pancreatic fibrosis are usual. The former causes portal hypertension, the incidence of which is reflected in the weight of the spleen, which is usually from two to three times enlarged, the average of 66 records being $416 \mathrm{~g}$. (Sheldon, 1935). In this case the histology of the spleen did not suggest portal hypertension, and the weight, $256 \mathrm{~g}$., was only slightly above the normal range.

Absence of Haemofuscin.-Haemofuscin is a common pigment in haemochromatosis and fails to give the free iron reaction. Pigmentation of the heart, gastric mucosal glands, and adrenal cortex is uncommon in haemosiderosis. This was found to a moderate degree in the present case, and more in keeping with idiopathic haemochromatosis.

\section{Discussion}

Uncritical acceptance of cases of haemochromatosis after blood transfusions has led to a false impression of the prevalence of this condition. Dubin (1955) suggested that the criteria required for the diagnosis should be the same as those required for idiopathic haemochromatosis, namely, (a) true cirrhosis, with unmistakable pseudo lobulation resulting in portal hypertension and fibrocongestive splenomegaly : $(b)$ pancreatic fibrosis ; and preferably $(c)$ diabetes mellitus.

When these criteria are used the majority of cases reported are unacceptable as examples of a condition identical with haemochromatosis.

There remains a small group of cases in which a true cirrhosis of the liver and pancreatic fibrosis has accompanied haemosiderosis. These cases still differ in that the distribution of iron is mainly in reticulo-endothelial cells as opposed to its location primarily in epithelial tissues in haemochromatosis, and also in the absence of haemofuscin (Dubin, 1955).

Experimental evidence to support the contention that excessive iron deposits in transfusion siderosis are of themselves the primary cause of the hepatic and pancreatic fibrosis has not been forthcoming, despite the researches of Brown, Moore, Reynafarje, and Smith (1950), Cappell (1930), Polson (1933), and Wyatt and Howell (1953). Further doubt has been raised by the lack of correlation generally recognized between the amount of iron administered intravenously and the development of haemochromatosis, a presumption illustrated by the case reported by Chesner (1946). It is also remarkable that many tissues are free from damage both in haemochromatosis and haemosiderosis despite heavy deposition of iron, and massive pulmonary siderosis from inhalation of iron does not cause pulmonary fibrosis (Doig, 1950).

It must be accepted that cases will occur which are clinically indistinguishable from primary haemochromatosis, and in some few of these the diagnosis has withstood a careful necropsy and 
critical histological examination of the tissues. It may be that the toxic action of iron is dependent on various factors such as the amount of iron administered (Finch, Hedsted, Kinney, Thomas, Rath, Haskins, Finch, and Fluharty, 1950; Morningstar, 1955), the route of its entry, or the duration of its presence in the tissues (Schwartz, 1956). Haemofuscin may not be important in considering the toxicity of iron, as this pigment is generally considered to be free of iron (Sheldon, 1935).

The following interesting problems remain unsolved :

(a) The toxicity to the tissues of iron compounds; (b) the cause of hepatic cirrhosis and pancreatic fibrosis in idiopathic haemochromatosis; (c) the incidence of haemochromatosis after blood transfusions.

Further study may be helped by the careful reporting of critically examined cases.

\section{Summary}

A case of transfusional haemosiderosis simulating haemochromatosis is reported.

The points of difference between this case and idiopathic haemochromatosis are enumerated, and various similarities noted.

The evidence for and against the toxicity of iron in the tissues is presented.

The literature on the subject is briefly reviewed.
We wish to thank Dr. W. Stokes and Dr. H. J. Harris for permission to publish this case and for valuable advice and criticism. We are grateful to Dr. C. L. Greenbury, who supervised the numerous haematological investigations and blood transfusions, to Dr. L. Nunn for assistance with the iron analyses, to Mr. Mason for help with the photomicrographs, and to Miss K. Smith for secretarial assistance.

\section{REFERENCES}

Aufderheide, A. C., Horns, H. L., and Goldish, R. J. (1953). Blood, $8,824$.

Brown, E. B., Moore, C. V., Reynafarje, C., and Smith, D. E. (1950) J. Amer. med. Ass., 144, 1084.

Cappell, D. F. (1930). J. Path. Bact., 33, 175.

Chesner, C. (1946). J. Lab. clin. Med. ,31, 1029.

Cottier, H. (1952). Schweiz. med. Wschr., 82, 873.

Doig, A. T. (1950). Arch. belges Méd. soc., 8, 442.

Dubin, I. N. (1955). Amer. J. clin. Path., $25,514$.

Finch, C. A., Hedsted, M., Kinney, T. D., Thomas, E. D., Rath, C. E., Haskins, D., Finch, S., and Fluharty, R. G. (1950). Blood, 5, 983.

Goldish, R. J., and Aufderheide, A. C. (1953). Ibid., 8, 837.

Hawk, P. B., Oseir, B. L., and Summerson, W. H. (1947). Practical Physiological Chemistry, 12th ed. Blakiston, Philadelphia.

Kleckner, M. S., Baggenstoss, A. H., and Weir, J. F. (1954). Amer. J. Med., 16, 382.

- Kark, R. M., Baker, L. A., Chapman, A. Z., Kaplan, E., and Moore, T. J. (1955). J. Amer. med. Ass., 157, 1471.

Morningstar, W. A. (1955). A.M.A. Arch. Path., 59, 355.

Muirhead, E. E., Crass, G., Jones, F., and Hill, J. M. (1949). Arch. intern. Med., 83, 477.

Pengelly, C. D. R., and Jones, P. (1956). Lancet, 2, 445.

Polson, C. (1933). Brit. J. exp. Path., 14, 73.

Schwartz, S. O. (1956). Amer. J. clin. Path., 26, 744.

_ and Blumenthal, S. A. (1948). Blood, 3, 617.

Sheldon, J. H. (1935). Haemochromatosis. Oxford University Press, London.

Wyatt, J. P., and Howell, J. (1953). A.M.A. Arch. Path., 55, 466.

Mighton, H. K., and Moragues, V. (1950). Amer. J. Path., 26,883 . 